\title{
A protocol for sonication-assisted Agrobacterium rhizogenes- mediated transformation of haploid and diploid sugar beet (Beta vulgaris L.) explants*
}

\author{
Magdalena Klimek-Chodacka and Rafal Baranski ${ }^{\bowtie}$ \\ Institute of Plant Biology and Biotechnology, Faculty of Horticulture, University of Agriculture in Krakow, Kraków, Poland
}

\begin{abstract}
Hairy root cultures obtained after Agrobacterium rhizogenes-mediated genetic transformation can serve as a model system for studying plant metabolism and physiology, or can be utilized for the production of secondary metabolites. So far no efficient protocol of hairy root development in sugar beet has been publically released. In this work, two $A$. rhizogenes strains (A4T and LBA1334) carrying a binary vector pBIN-m-gfp5-ER or pCAMBIA1301 possessing gfp and uidA reporter genes were used to transform petiole explants of haploid and diploid sugar beet genotypes. Five treatment combinations of sonicated-assisted Agrobacterium-mediated transformation were compared. Hairy roots appeared on $0 \%$ to $54 \%$ of explants depending on the treatment combination used. The highest frequency was achieved when explants of a diploid genotype were sonicated for $15 \mathrm{~s}$ in the inoculum containing $A$. rhizogenes of $\mathrm{OD}_{600}=0.5$ and then co-cultured for three days. Using the same treatment combinations the explants of haploid genotypes developed hairy roots with the frequency ranging from $10 \%$ to $36 \%$. Transformation efficiency was independent on the bacterial strain used. The results indicate that haploid sugar beet explants are amenable to transformation using $A$. rhizogenes, and that the efficiency of that process can be increased by applying short ultrasound treatment.
\end{abstract}

Key words: genetic modification, hairy root, SAAT, ultrasound

Received: 15 October, 2013; revised: 11 March, 2014; accepted: 17 March, 2014; available on-line: 22 March, 2014

\section{INTRODUCTION}

Sugar beet is an important agricultural crop cultivated in 2012 on a total area of 4.9 million hectares, predominantly in Europe (FAOSTAT). It is mainly used for sugar production, but a number of by-products, such as leaves, molasses, sugar beet pulp are successfully used as fertilizers, animal feed or in food industry (Smigocki et al., 2008). For several years, sugar beet has been also used for ethanol and biofuel production (Bessou et al., 2011).

Breeding new sugar beet varieties aims both at increase yield (polyploid varieties) and development of varieties with desirable traits such as resistance to pests and diseases and increased tolerance to abiotic stress (Biancardi et al., 2005). Sugar beet breeding process is difficult because of biennial life cycle of the species, high inbreeding depression and, additionally, by a limited range of available genetic variation. In recent decades, biotechnological techniques, including tissue cultures, transgenesis and molecular assisted selection have been successfully incorporated in breeding programs, for example by the production of doubled haploid (DH) lines useful for creation of hybrid varieties (Bosemark, 2007). Genetically modified (GM) H7-1 variety characterized by herbicide resistance was successfully commercialized in USA in 2008 and dominated sugar beet production. It is grown on $95 \%$ sugar beet plantation area in USA (Nehls et al., 2010).

H7-1 variety was developed in a process of Agrobacterium tumefaciens-mediated transformation (Dillen et al., 2013). A. tumefaciens is the most frequent vector used to deliver heterologous genes into a host plants. However, sugar beet is considered as one of the highly recalcitrant species to Agrobacterium. Thus, there is only a limited number of reports showing successful transformation and development of GM sugar beet plants (Smigocki et al., 2008). Several factors affect the efficiency of sugar beet transformation with the host plant genotype being one of the most critical one, what is explained by a high sugar beet heterozygosity. In comparison to other species, publicly released protocols of sugar beet transformation are inefficient and time consuming, and the GM plant production requires at least two years (Gurel et al., 2008).

A. rhizogenes is another bacteria capable of plasmid T-DNA transfer to higher plants and causing hairy root syndrome that can be utilized for the development of GM plant tissue. The appearance of hairy roots at the infection site of a plant explant occurs usually within two to four weeks after the inoculation. The excised hairy roots can be maintained on hormone free media where they grow extensively (Britton et al., 2008). An evident drawback of the use of $A$. rbizogenes is the need to force hairy root tissue to redirect its morphogenesis towards shoot development that is often difficult because of the presence of a high level of endogenous auxins (Giri \& Narasu, 2000, Ninković et al., 2010). In sugar beet there has been no reports showing shoot morphogenesis from hairy roots so far. Nevertheless,

e-mail: r.baranski@ogr.ur.krakow.pl

*Presented at the 5th Central European Congress of Life Sciences "EUROBIOTECH 2013", Kraków, Poland.

Abbreviations: BAP, 6-benzylaminopurine; $\mathrm{DH}$, doubled haploid; GFP, green fluorescent protein; GM, genetically modified; GUS, $\beta$-glucuronidase; NAA, 1-naphthaleneacetic acid; OD, optical density; SAAT, sonication-assisted Agrobacterium-mediated transformation 
sugar beet hairy root cultures were used in research to answer questions related to agricultural problems like plant-pathogen and plant-pest interactions (Cai et al., 2003). Additionally, hairy roots can be used for the production of secondary metabolites as demonstrated in red beet (Taya et al., 1992, Rudrappa et al., 2005). The efficiency of transgenic hairy roots is dependent on a number of factors, such as bacterial strain, genotype, type of explant, condition and duration of coculture with bacteria. Most of those factors have not been studied extensively in $A$. rhizogenes-mediated sugar beet genetic transformation. Also, there are no reports available on the use of ultrasound treatment to increase efficiency of sugar beet Agrobacterium-mediated transformation. Sonication-assisted Agrobacterium-mediated transformation (SAAT) is a procedure utilizing ultrasounds to help bacteria interfere with plant cells. It is postulated that brief ultrasonic treatment results in the formation of micro wounds on the surface of explants and the secreted phenolic compounds enhance transformation. Wounds make explant penetration by bacteria also more feasible. SAAT was successfully used for genetic transformation in plant species particularly considered as resistant to Agrobacterium (Liu et al. 2006, Pathak \& Hamzah, 2008).

In the present paper we compare several SAAT procedures using $A$. rhizogenes for the development of sugar beet hairy roots. We indicate the most efficient protocol for genetic transformation of haploid and doubled haploid genotypes.

\section{MATERIALS AND METHODS}

Plant material and culture conditions. Three haploid (Nos. 168, 169, 170) and one DH (No. 24) sugar beet (Beta vulgaris L.) genotypes were provided by Kutnowska Hodowla Buraka Cukrowego w Straszkowie (KHBC) breeding company, Straszkow, Poland. Haploids were produced via gynogenesis from unpollinated ovules and the $\mathrm{DH}$ genotype was obtained by diploidization of another haploid shoot as described before (KlimekChodacka \& Baranski, 2013).

All shoots were micropropagated by dividing into separate rosettes with intact meristems every three weeks. The shoots were placed on $0.7 \%$ agar-solidified $\mathrm{Mu}-$ rashige and Skoog (1962) salts and vitamins medium (MS; Duchefa Biochemie) supplemented with $0.3 \mathrm{mg} \mathrm{l}^{-1}$ 6-benzylaminopurine (BAP; Sigma), $0.1 \mathrm{mg} \mathrm{l}^{-1}$ 1-naphthaleneacetic acid (NAA; Sigma), $0.3 \mathrm{mg}^{-1}$ thiamine (Sigma) and $30 \mathrm{~g}^{-1}$ sucrose; $\mathrm{pH}$ 5.8. To prevent bacterial contamination $200 \mathrm{mg} \mathrm{l}^{-1}$ cefotaxime (Polfa, Tarchomin) was added to the medium. Micropropagated shoots were cultured in $500 \mathrm{ml}$ containers at $25 \pm 1^{\circ} \mathrm{C}$ under a 16 hrs photoperiod of 1:1 Daylight (Philips) and Fluora (Osram) fluorescent tubes $\left(55 \mu \mathrm{mol} \mathrm{m} \mathrm{m}^{-2} \mathrm{~s}^{-1}\right)$.

Agrobacterium strains and plasmids. Agrobacterium rhizogenes strains A4T (McInnes et al., 1989) and LBA1334 (Offringa et al., 1986) both harboring pBIN-mgfp5-ER plasmid (thereafter called A4T-gfp and LBA1334-gfp, respectively) and strain A4T with plasmid pCAMBIA1301 (thereafter called A4T-gus) were used. The T-DNA of pBIN-mgfp5-ER plasmid contained m-gfp5-ER gene coding for a green fluorescence protein and $n p t I$ gene conferring plant resistance to kanamycin. The T-DNA of pCAMBIA1301 plasmid contained $\beta$-glucuronidase (uid $A$ ) gene and $h p t \mathrm{II}$ gene conferring plant resistance to hygromycin. Both plasmids possessed kanamycin resistance gene expressed in bacteria.
Bacteria were grown overnight at $25^{\circ} \mathrm{C}$ in liquid LuriaBertani medium supplemented with $50 \mathrm{mg} \mathrm{l}^{-1}$ rifampicin and $50 \mathrm{mg} \mathrm{l}^{-1}$ kanamycin with shaking $(200 \mathrm{rpm})$. Bacteria were harvested by centrifugation at room temperature for $10 \mathrm{~min}$ and then resuspended in MS salts and vitamins inoculation medium supplemented with $0.4 \mathrm{mg} \mathrm{l}^{-1}$ $\mathrm{NAA}$, and $30 \mathrm{~g}^{-1}$ sucrose, $100 \mu \mathrm{M}$ acetosyringone and the inoculum was adjusted to $\mathrm{OD}_{600}=0.5$. After additional $1 \mathrm{~h}$ shaking incubation the inoculum was diluted to the final bacteria concentration $\left(\mathrm{OD}_{600}=0.05\right.$ or 0.5$)$.

Transformation procedure. Petiole and midrib explants were obtained from two-week-old shoots micropropagated in vitro and immersed in the inoculation medium containing one of the bacterial strain, or in the inoculation medium free of Agrobacterium. After sonication (15-240 s) explants were gently shaken for $15 \mathrm{~min}$. When sonication was carried out in a solution without Agrobacterium, the inoculum was added after ultrasonic treatment followed by gentle shaking for $15 \mathrm{~min}$. The explants were then blotted on sterile filter paper and transferred to Petri dishes containing $0.7 \%$ agar-solidified MS medium with $30 \mathrm{~g} \mathrm{l}^{-1}$ sucrose and $100 \mu \mathrm{M}$ acetosyringone and were co-cultured for 3 or 4 days in the dark at $25 \pm 2{ }^{\circ} \mathrm{C}$. Next, explants were transferred to a fresh medium supplemented additionally with $400 \mathrm{mg} \mathrm{l}^{-1}$ cefotaxime and $100 \mathrm{mg} \mathrm{l}^{-1}$ timentin for Agrobacterium elimination. Ten explants were placed in each Petri dish and experiments were set up in 5-14 replications. Cultures were kept in the dark at $25 \pm 2{ }^{\circ} \mathrm{C}$. Emerging hairy roots were excised out of explants and cultured using the same medium and conditions, and were subcultured every three weeks.

GUS staining and GFP detection. $\beta$-glucuronidase activity in hairy roots obtained after transformation with strain A4T-gus was detected by histochemical staining essentially according to Jefferson et al. (1987). The transformed hairy roots were incubated overnight at $37^{\circ} \mathrm{C}$ in $50 \mathrm{mM}$ sodium phosphate buffer ( $\mathrm{pH} 7.0$ ) with $1 \%$ Triton X-100 (Sigma-Aldrich) and 2mM 5-bromo-4-chloro3-indolyl glucuronide (Duchefa) as a substrate.

The presence of GFP protein in hairy roots obtained after transformation with strains A4T-gfp and LBA1334gfp was detected by observation of green fluorescence of hairy roots illuminated with UV lamp (UVP-100BP).

DNA isolation and molecular analysis of transformants. Genomic DNA was isolated from transgenic hairy roots using a CTAB method described by Rogers and Bendich (1988). The presence of transgenes was confirmed by PCR reaction using uid $A$ and $g / p$ gene specific primers that amplified $1202 \mathrm{~kb}$ and $500 \mathrm{~kb}$ products, respectively (Hamill et al., 1991, Higgins et al., 2006). $10 \mu \mathrm{l}$ PCR reactions contained $1 \mu \mathrm{l} 10 \mathrm{x}$ buffer, 250 $\mu \mathrm{M}$ of each dNTP, $0.5 \mu \mathrm{M}$ of each primer and $0.5 \mathrm{U}$ Dream'Taq Green DNA Polymerase (ThermoScientific). PCR was performed in the Eppendorf Master Gradient thermocycler by applying denaturation at $94^{\circ} \mathrm{C}$ for $4 \mathrm{~min}$ followed by 35 cycles $\left(45 \mathrm{~s}\right.$ denaturation at $94^{\circ} \mathrm{C} ; 30 \mathrm{~s}$ primer annealing at $56^{\circ} \mathrm{C}$ for $g f p$ primers or $65^{\circ} \mathrm{C}$ for vid $A$ primers; 60 s elongation at $72^{\circ} \mathrm{C}$ ) and then final 5 min elongation at $72^{\circ} \mathrm{C}$. A potential bacterial contamination was verified using the same PCR parameters as for widA gene and applying primers specific to virD2 sequence (Haas et al., 1995). Amplified products were separated by electrophoresis in $1 \%$ agarose gel in 1xTBE buffer. For Southern blot hybridization, $5 \mu \mathrm{g}$ DNA was digested with restriction enzymes (HindIII or BamHI for hairy roots obtained with 102 and 105 or 131 Agrobacterium strain, respectively), separated in $1 \%$ agarose gel and transferred onto nylon membrane (Roche). Probes 
were obtained using midA and gfp gene specific primers (Hamill et al., 1991 and Lipp et al., 2001, respectively) and were labeled with DIG using PCR DIG Probe Synthesis kit (Roche). Plasmid DNA, non-restricted DNA from genetically modified plants and control DNA from sugar beet were used for reference. After hybridization with labeled probes at $65^{\circ} \mathrm{C}$, detection of signals was performed using a chemiluminescent substrate according to the manufacturer instructions.

Statistical analysis. Treatment means were calculated and accompanied by their standard errors. Data were subjected to one-way ANOVA available in the Statsoft Statistica v.8.0 package. Percentage data were transformed using Bliss transformation $\arcsin \sqrt{x}_{\mathrm{x}}$ before the analysis.

\section{RESULTS AND DISCUSSION}

In the process of genetic transformation wounding of plant tissue plays a crucial role as the released plant metabolites may activate a cascade of bacterial virulence genes (Gaba et al., 2006). In plants that are susceptible to Agrobacterium tissue wounding done during explants preparation is thus usually sufficient. However, in recalcitrant species like sugar beet, it is necessary to use additional mechanical injuries using needles or by tissue scratching (Hoshi et al., 2004). Alternatively, explants are treated with ultrasounds, which disrupt tissue. Based on our preliminary experiments, genetic transformation without ultrasound treatment of sugar beet explants was inefficient. In control, explants were inoculated with bacteria, but the sonication step was omitted. Hairy roots usually did not occur at all or in some replications they occurred on individual explants only. After SAAT the development of hairy roots was abundant. They started to emerge usually 10 days after the inoculation mainly at the explant wounding site (Fig. 1). The number of hairy roots ranged from 1 to 12 per explant. Hairy roots were characterized by a typical phenotype described in other species (Giri \& Narasu, 2000). They grew rapidly, formed lateral branches and showed lack of geotropism. After transfer to a hormone free medium they continue fast growth and proliferation.

Comparison of SAAT treatment variants using diploid sugar beet revealed that explants developed hairy roots with various frequency ranging, on average, from $6 \%$ to
Table 1 Percent of diploid explants (genotype No. 24) developing hairy roots after SAAT using inoculum with LBA1334-gfp strain depending on duration of ultrasonic treatment.

The bacterial inoculum of $\mathrm{OD}_{60}=0.05$ or 0.5 was added before sonication, and co-culture lasted for 3 days. Means \pm standard error, number of explants per treatment $n=100$

\begin{tabular}{lllll}
\hline \multirow{2}{*}{$\begin{array}{l}\text { Duration of ultrasonic } \\
\text { treatment }[\mathrm{s}]\end{array}$} & \multicolumn{4}{l}{$\mathrm{OD}_{600}$ of bacterial inoculum } \\
\cline { 2 - 5 } & 0.05 & \multicolumn{3}{c}{0.5} \\
\hline 15 & 19.0 & \pm 3.79 & 54.0 & \pm 3.40 \\
\hline 30 & 9.0 & \pm 2.77 & 52.0 & \pm 5.33 \\
\hline 60 & 7.0 & \pm 2.60 & 33.0 & \pm 4.73 \\
\hline 120 & 6.0 & \pm 2.67 & 8.0 & \pm 2.49 \\
\hline 240 & 7.0 & \pm 2.60 & 7.0 & \pm 2.13 \\
\hdashline Mean & 9.6 & \pm 1.43 & 30.8 & \pm 3.34 \\
\hline
\end{tabular}

54\% (Table 1). In general, short ultrasound treatments lasting for $15 \mathrm{~s}$ and $30 \mathrm{~s}$ better stimulated hairy root development than 1-4 min treatments. Also, high optical density of inoculum promoted hairy root formation but at short ultrasonic treatments only. Ultrasounds cause tissue disruption leading finally to its damage as shown in other plant species (Liu et al., 2006). Thus, short sonication is recommended, although its time must be adjusted to explant type. Trick \& Finer (1997) indicated that the efficiency of transformation process is independent on the presence of Agrobacterium during sonication. Hence most of SAATs is usually carried out in the inoculation medium already containing bacteria (Pathak \& Hamzah, 2008). In contrast, our results indicate that higher percentage of explants form almost two times more hairy roots when sonication is applied to explants immersed in the inoculum than when Agrobacterium is added after sonication $(P<0.05)$. Such reaction indicates that ultrasounds promote explant penetration by bacteria.

Time of explant co-culture with bacteria is essential for proper T-DNA transfer to a host cell. One to two day co-culture is usually allowed before Agrobacterium is eliminated from the culture. Extended time may be beneficial for species recalcitrant to Agrobacterium as shown by Mishutkina et al. (2010) who got higher efficiency after a 4-day co-culture. In our experiments a 3-day co-culture was found more advantageous than a 4-day co-culture.

Table 2. SAAT efficiency of three haploid explants immersed in three bacterial inocula of $\mathrm{OD}_{600}=0.5$ and after a 3-day co-culture. Means \pm standard error

\begin{tabular}{|c|c|c|c|c|c|c|}
\hline \multirow{2}{*}{$\begin{array}{l}\text { Haploid } \\
\text { genotype } \\
168\end{array}$} & \multirow{2}{*}{$\begin{array}{l}\text { Agrobacterium strain } \\
\text { A4T-gfp }\end{array}$} & \multirow{2}{*}{$\begin{array}{l}\text { No. of explants } \\
80\end{array}$} & \multicolumn{2}{|c|}{$\begin{array}{l}\text { Percentage of explants } \\
\text { forming hairy roots }\end{array}$} & \multirow{2}{*}{$\begin{array}{l}\text { Total number of } \\
\text { hairy roots }\end{array}$} & \multirow{2}{*}{$\begin{array}{l}\text { Percentage of } \\
\text { gfp/gus }+ \\
\text { hairy roots } \\
\\
53.8\end{array}$} \\
\hline & & & 28.8 & \pm 9.72 & & \\
\hline 168 & LBA1334-gfp & 130 & 30.8 & \pm 5.00 & 187 & 64.2 \\
\hline 168 & A4T-gus & 130 & 30.0 & \pm 4.39 & 212 & 35.9 \\
\hline 169 & A4T-gfp & 100 & 17.0 & \pm 5.78 & 38 & 36.8 \\
\hline 169 & LBA1334-gfp & 50 & 36.0 & \pm 5.10 & 28 & 64.3 \\
\hline 169 & A4T-gus & 50 & 10.0 & \pm 0 & 13 & 0 \\
\hline 170 & A4T-gfp & 90 & 11.1 & \pm 3.89 & 20 & 50.0 \\
\hline 170 & LBA1334-gfp & 140 & 10.0 & \pm 2.96 & 29 & 62.1 \\
\hline 170 & A4T-gus & 140 & 16.4 & \pm 3.87 & 57 & 36.4 \\
\hline Total/Mean & & 2270 & 20.8 & \pm 1.87 & 701 & 54.8 \\
\hline
\end{tabular}



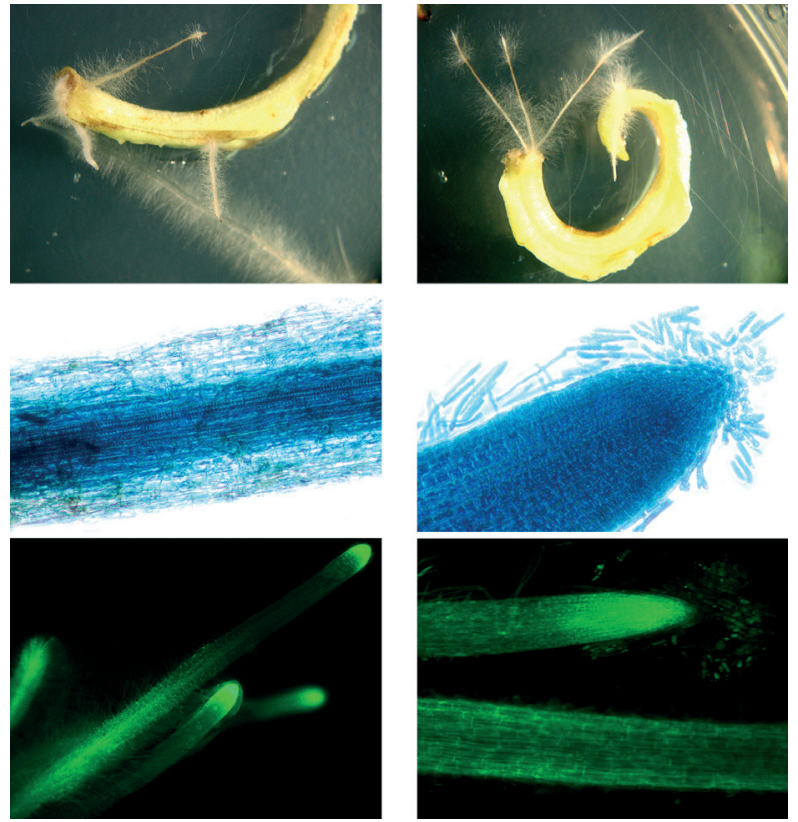

Figure 1. Hairy roots developing at wounding sites of haploid genotype No. 170 explants after SAAT (upper). Transgenic hairy roots expressing uidA gene and stained in blue after $\beta$-glucuronidase assay (middle) and expressing gfp gene visible by green fluorescence in UV light (bottom).

This later resulted in a reduced number of hairy roots by $30 \%$ and additionally caused tissue colonization by bacteria and decay similarly as observed by Jacq et al. (1993).

In total, 226 hairy roots were obtained from 500 explants and 107 out of them (47\%) showed green fluorescence in UV light that confirmed transfer of the gfp gene from Agrobacterium and its expression in plant tissue. When short sonication times (15 s and $30 \mathrm{~s}$ ) were applied, the expression of GFP was observed in 54.3\% and $47.5 \%$ of hairy roots, respectively.

SAAT conditions found the most effective for diploid explants (15 s sonication in the presence of $A$. rhizogenes inoculum of $\mathrm{OD}_{600}=0.5,3$-day co-culture) were subsequently verified using explants of three haploid genotypes. Other two bacterial strains were also additionally used. The mean transformation efficiency of haploids was $20.8 \%$ and significantly depended on the genotype $(P<0.005)$, but not on the bacterial strain used $(P=0.23)$ (Table 2). On average, hairy roots were formed most effectively on explants of 168 genotype $(30.0 \%)$. The other two genotypes 169 and 170 responded with lower efficiency $20 \%$ and $12.7 \%$, respectively, and the difference between them was significant. Both haploid genotypes were derived from two ovules of the same donor plant, which was not closely related to a donor of 168 genotype. Thus, the observed variation was due to genetic background of explants, a common factor identified in most research (Gurel et al., 2008; Smigocki et al., 2008).

In total, 701 hairy roots were obtained from haploid explants (Table 2). The expression of transgenes ( $g / p$ or gus) was observed in $54.8 \%$ of the examined roots (Fig. 1), that a similar rate as for the diploid explants No. 24. The highest percentage of roots exhibiting transgene expression was obtained using A4T-gfp strain, independently on the explant genotype, and for which green fluorescence in UV light was observed in over $60 \%$ of hairy roots.

Results of PCR reactions carried out using primers specific to the transgenes confirmed T-DNA transfer in 26 out 44 hairy roots (59\%), as amplified fragments had expected sizes (Fig. 2). For 13 hairy root clones no PCR products of the expected size were obtained. In further five clones PCR results remained ambiguous as virulence genes were detected indicating contamination of the plant material with bacterial DNA. Southern hybridization confirmed integration of the transgenes, which copy
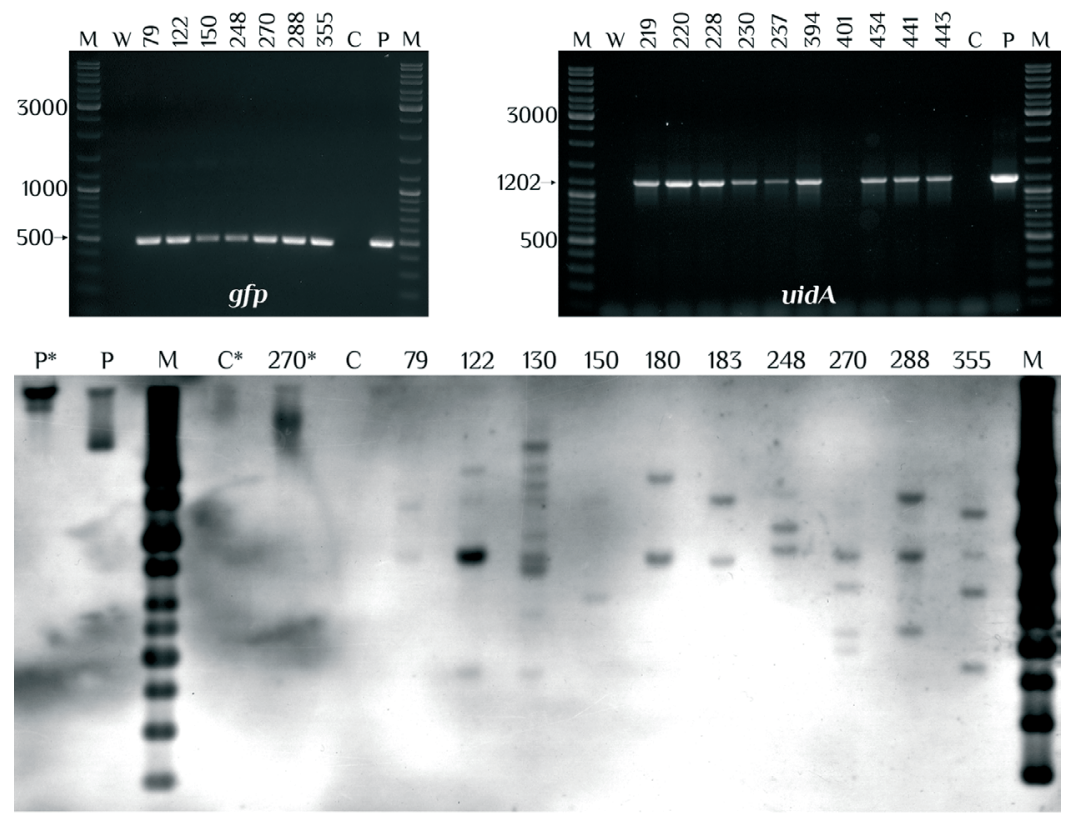

Figure 2. Products of PCR amplification of gfp and uidA fragments using gene specific primers (upper) and Southern blot of hairy root DNA obtained after transformation of haploid genotypes with A4T-gfp and LBA1334-gfp strains and hybridized with gfp probe (bottom).

M - DNA Ladder Mix, W - water, C — DNA of non-transformed plant, P - pBIN-mgfp5-ER plasmid, 79-443 — DNA of independent transgenic hairy roots, *undigested DNA. 
number varied from one to nine depending on the transformation event (Fig. 2).

So far, haploid explants have never been used in sugar beet genetic transformation in contrast to the use of diploid tissues (Kishchenko et al., 2005, Jafari et al., 2009). Haploids may be valuable material for genetic transformation as diploidization induced after a gene transfer would lead to the development of a homozygous tissue, including a transgene locus. Thus, the locus becomes fixed (Dunwell, 2010). Haploids are routinely produced and utilized by sugar beet breeding companies for the development of $\mathrm{DH}$ lines. Our results show for the first time that sugar beet haploid tissue is amenable to genetic transformation using $A$. rhizogenes and that its efficiency can be enhanced using SAAT method. This opens new perspectives for a fast development of homozygous GM sugar beet tissue useful primarily in basic research. Its further application can be possible once a protocol for shoot morphogenesis from sugar beet hairy roots is released.

\section{Acknowlegments}

The Authors thank Ms. Iwona Zapała for her excellent technical assistance.

This work was supported by the Polish Ministry of Agriculture and Rural Development (Decision No. HOR hn-801-10/13).

\section{REFERENCES}

Bessou C, Ferchaud F, Gabrielle B, Mary B (2011) Biofuels, greenhouse gases and climate change. A review. Agron Sustain Dev 31: $1-79$.

Biancardi EC, Larry GS, George NB, Marco D (2005) Genetics and breeding of sugar beet. Science Publishers, Enfield NH, USA.

Bosemark NO (2007) Genetics and breeding. In Sugar beet. Draycott AP, ed, pp 50-88. Blackwell Publishing Ltd, Oxford, UK.

Britton M, Escobar M, Dandekar A (2008) The oncogenes of Agrobacterium tumefaciens and Agrobacterium rbizogenes. In Agrobacterium: from biology to biotechnology. Tzfira T, Citovsky V, eds, pp 523-563, Springer New York.

Cai D, Thurau T, Tian Y, Lange T, Yeh KW, Jung C (2003) Sporamin-mediated resistance to beet cyst nematodes (Heterodera schachtii Schm.) is dependent on trypsin inhibitory activity in sugar beet (Beta vulgaris L.) hairy roots. Plant Mol Biol 51: 839-849.

Dillen K, Demont M, Tillie P, Rodriguez Cerezo E (2013) Bred for Europe but grown in America: the case of GM sugar beet. New Biotechnology 30: 131-135.

Dunwell JM (2010) Haploids in flowering plants: origins and exploitation. Plant Biotechnol J 8: 377-424.

Gaba V, Kathiravan K, Amutha S, Singer S, Xiaodi X, Ananthakrishnan G (2006) The uses of ultrasound in plant tissue culture. In Plant Tissue Culture Engineering. Dutta Gupta S, Ibaraki Y, eds, pp 417-426, Springer Netherlands.

Giri A, Narasu ML (2000) Transgenic hairy roots: recent trends and applications. Biotechnol Adv 18: 1-22.

Gurel C, Gurel S, Lemaux PG (2008) Biotechnology applications for sugar beet. Crit Rev Plant Sci 27: 108-140.

Hamill JD, Rounsley S, Spencer A, Todd G, Rhodes MJC (1991) The use of the polymerase chain reaction in plant transformation studies. Plant Cell Rep 10: 221-224.

Haas JH, Moore LW, Ream W, Manulis S (1995) Universal PCR primers for detection of phytopathogenic Agrobacterium strains. Appl Environ Microbiol 61: 2879-2884.
Higgins JD, Newbury HJ, Barbara DJ, Muthumeenakshi S, Puddephat IJ (2006) The production of marker-free genetically engineered broccoli with sense and antisense ACC synthase 1 and ACC oxidases 1 and 2 to extend shelf-life. Mol Breed 17: 7-20.

Hoshi Y, Kondo M, Mori S, Adachi Y, Nakano M, Kobayashi H (2004) Production of transgenic lily plants by Agrobacterium-mediated transformation. Plant Cell Rep 22: 359-364.

Jacq B, Lesobre O, Sangwan R, Sangwan-Norreel B (1993) Factors influencing T-DNA transfer in Agrobacterium-mediated transformation of sugarbeet. Plant Cell Rep 12: 621-624.

Jafari M, Norouzi P, Molboobi MA, Ghareyazie B, Valizadeh M, Mohammadi SA, Mousavi M (2009) Enhanced resistance to a lepidopteran pest in transgenic sugar beet expressing synthetic cry $1 A b$ gene. Eupbytica, 165: 333-344.

Jefferson R (1987) Assaving chimeric genes in plants: The GUS gene fusion system. Plant Mol Biol Rep 5: 387-405.

Kishchenko EM, Komarnitskii IK, Kuchuk NV (2005) Production of transgenic sugarbeet (Beta vulgaris L.) plants resistant to phosphinothicin. Cell Biol Int, 29: 15-19.

Klimek-Chodacka M, Baranski R (2013) Comparison of haploid and doubled haploid sugar beet clones in their ability to micropropagate and regenerate. Electron I Biotechnol 16: 1-1. Available from: http:/ / www.scielo.cl/scielo.php? script=sci_arttext\&pid=S071734582013000200001\&lng=en. http://dx.doi.org/10.2225/voll6issue2-fulltext-3.

Lipp M, Bluth A, Eyquem F, Kruse L, Schimmel H, Van den Eede G, Anklam E (2001) Validation of a method based on polymerase chain reaction for the detection of genetically modified organisms in various processed foodstuffs. Eur Food Res Technol 212: 497-504.

Liu Y, Yang H, Sakanishi A (2006) Ultrasound: Mechanical gene transfer into plant cells by sonoporation. Biotechnol Adv, 24: 1-16.

McInnes E, Davey MR, Mulligan BJ, Davies K, Sargent AW, Morgan AJ (1989) Use of a disarmed Ri plasmid vector in analysis of transformed root induction. J Exp Bot 40: 1135-1144.

Mishutkina IaV, Kamionskaia AM, Skriabin KG (2010) Generation of sugar beet transgenic plants expressing bar gene. Appl Biochem Microbiol, 46: 80-86.

Murashige T, Skoog F (1962) A revised medium for rapid growth and bioassays with tobacco tissue cultures. Physiol Plant, 1: 473-497.

Nehls R, Kraus J, Matzk A, Jansen R (2010) Transgenic varieties: Sugarbeet. Sugar Tech 12: 194-200.

Ninković S, Djordjević T, Vinterhalter B, Uzelac B, Cingel A, Savić J, Radović S (2010) Embryogenic responses of Beta vulgaris L. callus induced from transgenic hairy roots. Plant Cell Tiss Organ Cult 103: 81-91.

Offringa IA, Melchers LS, Regensburg-Tuink AJG, Costantino P, Schilperoort RA, Hooykaas PJJ (1986) Complementation of Agrobacterium tumefaciens tumor-inducing aux mutants by genes from the $\mathrm{T}_{\mathrm{R}}-$ region of the Ri plasmid of Agrobacterium rbizogenes. Proc Nat Acad Sci USA 83: 6935-6939.

Pathak M, Hamzah R (2008) An effective method of sonication-assisted Agrobacterium-mediated transformation of chickpeas. Plant Cell Tiss Organ Cult 93: 65-71.

Rogers SO, Bendich AJ (1988) Extraction of DNA from plant tissues. Plant Mol Biol Manual A6: 1-10.

Rudrappa T, Neelwarne B, Kumar V, Lakshmanan V (2005) Peroxidase production from hairy root cultures of red beet (Beta vulgaris). Electron J Biotechnol 8: 185-196.

Smigocki A, Campbell L, Larson R, Wozniak C (2008) Sugar beet. In Compendium of Transgenic Crop Plants: Transgenic Sugar, Tuber and Fiber Crops. Kole C, Hall TC eds, pp 59-96. Blackwell Publishing, Oxford, UK.

Taya M, Mine K, Kino-Oka M, Tone S, Ichi T (1992) Production and release of pigments by culture of transformed hairy root of red beet. J Ferment Bioeng 73: 31-36.

Trick H, Finer J (1997) SAAT: sonication-assisted Agrobacterium-mediated transformation. Transgenic Res 6: 329-336. 